\title{
The complete control of murine pregnancy from embryo implantation to parturition
}

\author{
Jumpei Terakawa ${ }^{1,2}$, Takaho Watanabe ${ }^{3}$, Rutsuko Obara ${ }^{3}$, Makoto Sugiyama ${ }^{1,2}$, Naoko Inoue $^{1}$, \\ Yasushige Ohmori ${ }^{1}$, Yoshinao Z Hosaka ${ }^{2}$ and Eiichi Hondo ${ }^{1}$ \\ ${ }^{1}$ Laboratory of Animal Morphology, Division of Biofunctional Development, Graduate School of Bioagricultural \\ Sciences, Nagoya University, Nagoya 464-8601, Japan, ${ }^{2}$ Laboratory of Basic Veterinary Science, United Graduate \\ School of Veterinary Science, Yamaguchi University, Yamaguchi 753-8511, Japan and ${ }^{3}$ Hatano Research Institute, \\ Food and Drug Safety Center, Kanagawa 257-8523, Japan
}

Correspondence should be addressed to E Hondo; Email: ehondo@agr.nagoya-u.ac.jp

\begin{abstract}
The ovary is the main secretory source of progestin and estrogen and is indispensable to the maintenance of all events of pregnancy in mice. The purpose of this study was to control all processes of pregnancy in mice, from embryo implantation to parturition, without ovaries. The ovaries were removed before embryo implantation, and a single injection of medroxyprogesterone acetate (MPA) was given. Embryo implantation was induced by leukemia inhibitory factor, which can substitute $17 \beta$-estradiol $\left(E_{2}\right)$. Continuous exposure to $E_{2}$ was necessary at mid-pregnancy, when placentation was completed. All mice sustained pregnancy without ovaries before parturition, which was initiated by the removal of $E_{2}$ and MPA. Murine pregnancy is a complicated process involving embryo implantation, placentation, and parturition. Complete control of pregnancy was achieved with the simple treatment of MPA and $E_{2}$ after induction of embryo implantation. Here, time-dependent events in the uterus during pregnancy could be realized without the ovaries, because the initiation of each event could be stringently controlled by hormonal treatments.

Reproduction (2012) 143 411-415
\end{abstract}

\section{Introduction}

The ovary is the main secretory source of progestin and estrogen and is indispensable to maintenance of pregnancy throughout gestation in many mammals, including cows (Estergreen et al. 1967), goats (Meites et al. 1951), dogs (Verstegen-Onclin \& Verstegen 2008), and/or rabbits (Pickworth \& Lamming 1967). On the other hand, an ovariectomy at mid-pregnancy or the later trimester of pregnancy does not disrupt the process of pregnancy in several mammals, including humans (Csapo et al. 1972), monkeys (Albrecht et al. 2000), guinea pigs (Bland \& Donovan 1969), and/or mares (Hinrichs et al. 1987), whose progestin and estrogen are supplied by other tissues such as the placenta. In ovariectomized mares, a daily single injection of progesterone is sufficient to establish and maintain pregnancy after embryo transfer (Hinrichs et al. 1987). In addition, ovariectomized ferrets cannot sustain pregnancy with any steroid treatment $(\mathrm{Wu} \&$ Chang 1972). The steroid requirements for pregnancy are dependent on the animal species.

The ovary is absolutely necessary for murine pregnancy (Rubinstein \& Forbes 1963). In mice, serum progesterone levels increase with the progress of pregnancy, reach a peak at gestation day 16 (D16; the first day of pregnancy (D1) is determined as the morning a vaginal plug is observed in a female that had been housed with a male the previous evening), and rapidly decrease before parturition (Murr et al. 1974). A transient increase in $17 \beta$-estradiol $\left(E_{2}\right)$ at D4 is essential for embryo implantation (McCormack \& Greenwald 1974). Serum $E_{2}$ levels increase from mid-pregnancy to term and decline rapidly before delivery (Barkley et al. 1977). Ovariectomy at any time during pregnancy results in abortion in mice, even if progesterone is administered.

Here, we attempted to control murine pregnancy completely, from embryo implantation to parturition, using mice that were ovariectomized before the implantation period, with hormonal treatments.

\section{Results}

The number of implantation sites at the ninth day of experimental pregnancy day (ED9) was 10.2 \pm 4.2 $(n=11$, average \pm s.D.) after injection with leukemia inhibitory factor (LIF). The number of placenta or living fetuses at ED22 was verified in mice, inside which the $E_{2}$ implant and medroxyprogesterone acetate (MPA) were 
Table 1 Maintenance of pregnancy in ovariectomized mice with hormonal treatments.

\begin{tabular}{|c|c|c|c|c|c|c|}
\hline $\begin{array}{l}\text { Removal of } E_{2} \\
\text { (ED17) and } \\
\text { MPA (ED20) }\end{array}$ & $\begin{array}{c}\text { No. of } \\
\text { pregnant mice }\end{array}$ & $\begin{array}{l}\text { Pregnancy } \\
\text { rates }(\%)\end{array}$ & $\begin{array}{l}\text { Total no. of } \\
\text { placentas } \\
\text { (live; ED22) }\end{array}$ & $\begin{array}{c}\text { Birth } \\
\text { rates }(\%)\end{array}$ & $\begin{array}{l}\text { Total no. of } \\
\text { birth (live) }\end{array}$ & $\begin{array}{l}\text { Total no. of } \\
\text { MGs (ED24) }\end{array}$ \\
\hline- & 7 & 100 & $60(53)$ & 0 & $0(0)$ & N/A \\
\hline+ & 10 & 100 & N/A & 90 & $43(36)$ & 110 \\
\hline Normal pregnancy & 4 & 100 & N/A & 100 & $58(58)$ & 69 \\
\hline
\end{tabular}

$\mathrm{E}_{2}$, the silicone tube containing with $\mathrm{E}_{2} ; \mathrm{MPA}$, medroxyprogesterone acetate; MGs, the metrial glands; and N/A, not applicable.

left. All ovariectomized mice $(n=7)$ had formed the placenta $(8.6 \pm 7.2 /$ head, average \pm s.D. $)$, and 53 of 60 pups $(88.3 \%)$ were alive (Table 1$)$. Nine of ten mice underwent successful parturition by removal of the silicone tube containing $E_{2}$ and MPA (Table 1). One mouse died at ED19, although the pregnancy was sustained. Forty-three pups (4.8 $\pm 4.0 /$ head, average \pm S.D.) were delivered, of which $36(83.7 \%)$ were alive (Table 1). The number of the metrial glands $(11.0 \pm 3.7 /$ head, average \pm s.D.), which were counted after parturition, was consistent with the number of implantation sites at ED9 (Table 1).

Plasma levels of MPA were almost constant and not high through pregnancy (Fig. 1A) compared to those of progesterone during normal pregnancy (Murr et al. 1974). MPA was rapidly declined after ED20, at which MPA was removed for induction of the parturition, and not detectable at ED23 (Fig. 1A). The concentrations of $\mathrm{E}_{2}$ became slightly higher during ED11 and ED17 after the silicone tube was implanted (Fig. 1B). Elevation of $\mathrm{E}_{2}$ was observed after parturition (ED24, Fig. 1B).

The mammary glands were sparse among the fat tissue in ovariectomized mice (Fig. 2A) compared to that in the normal pregnant mice (Fig. 2B). Secreted milk was stored in the alveolus of ovariectomized mice, which is occasionally enlarged (Fig. 2A). The alveolar epithelium of these mice is thinner than the control (Fig. 2C and D).

\section{Discussion}

Successful pregnancy, from initiation of embryo implantation to parturition, was completely achieved artificially in ovariectomized mice by exogenous treatments according to the experimental procedure. LIF lies downstream of estrogen and is an essential factor of murine embryo implantation (Chen et al. 2000). Although female Lif-deficient mice are infertile, injection with LIF can recover the implantation process, and embryos are sustained to birth if the mother possesses ovaries (Chen et al. 2000). This effect is completely reflected by that of $E_{2}$ (Chen et al. 2000). The requirement for $E_{2}$ at the time of implantation is very low ( $<10$ ng/head; Milligan \& Finn 1997) and excess amounts of $E_{2}$ disrupt implantation. Therefore, we substituted LIF for $\mathrm{E}_{2}$ to facilitate implantation control. Our finding suggests that LIF priming at ED6 of pregnancy and simultaneous administration of progesterone (MPA) can sustain pregnancy at the earliest until ED11. Serum levels of MPA were almost constant after injection (Fig. 1A). This experimental model could be applied to precise analysis of trophoblast differentiation toward completion of placentation and/or vasculogenesis during placentation. Embryo implantation was also induced by other molecules such as cAMP except for $E_{2}$ in mice (Holmes \& Bergström 1975). Because pregnancy was not sustained with progesterone alone after cAMP-induced implantation, it was not determined whether cAMP was sufficient for complete embryo implantation (Holmes \& Bergström 1975). It might be due to failure of sustenance of pregnancy after mid-pregnancy.
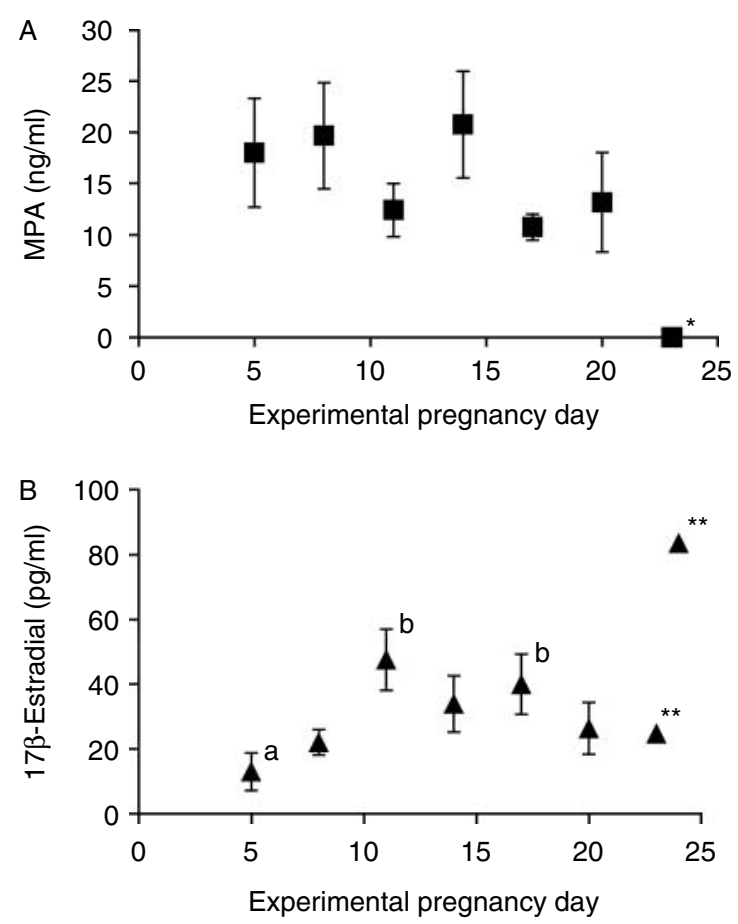

Figure 1 Plasma concentrations of medroxyprogesterone acetate (MPA; $A)$ and $17 \beta$-estradiol $\left(E_{2} ; B\right)$. No significant difference is observed in MPA from ED5 to ED20. The levels of $E_{2}$ are statistically higher at ED11 (b) and ED17 (b) compared to that of ED5 (a). There is significant difference between $\mathrm{a}$ and $\mathrm{b}(P<0.05)$. Average \pm s.E.M. $(n=3-5)$. *Under detection. ${ }^{*}$ The number of samples is two. 

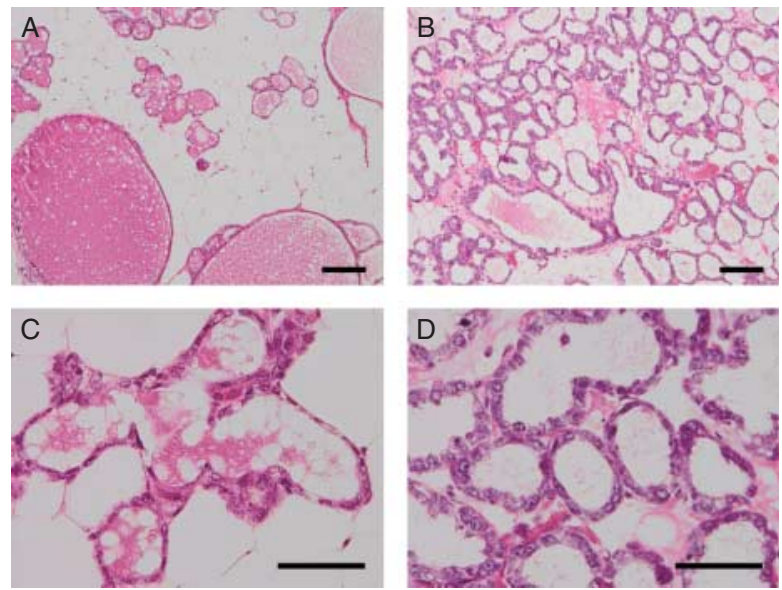

Figure 2 The mammary gland from ovariectomized mice at ED23 (A and C) and normal pregnant mice at D21 (B and D). The alveolus of the ovariectomized mice is sparse (A and $C$ ) compared to the normal alveolus (B and D). Scale bar $=100 \mu \mathrm{m}$ (A and B) and $50 \mu \mathrm{m}(C$ and D).

In addition to progesterone, estrogen, which lowers progesterone requirements, is necessary to sustain pregnancy in mid-pregnancy, during which placentation is completed in mice (Milligan \& Finn 1997). In this study, we used a silicone tube that could gradually release $E_{2}\left(\sim 20 \%\right.$ of the total amount of $E_{2}$ is released within 1 week; Okada et al. 2005), because a high dose of $E_{2}$ causes fetal death. The first single injection of MPA and transplantation of the silicone tube containing $E_{2}$ were sufficient to maintain placentation and the last trimester of pregnancy. The plasma concentration of $E_{2}$ was slightly higher when silicone tube was s.c. inserted (Fig. 1B). These $E_{2}$ levels were not inconsistent with that of normal mid-pregnancy, although $E_{2}$ was gradually increased toward term in normal pregnancy (Barkley et al. 1977). The results show that $84.3 \%$ of implantation sites formed the placenta (average implantation sites at ED9; 10.2 vs average placenta at ED22; 8.6). Several implantation sites would have been lost during midpregnancy in this study because spontaneous abortions occur during mid-pregnancy, even in a normal pregnancy (Kusakabe et al. 2008). This is a brand new model investigating the mechanism of spontaneous abortion during mid-pregnancy.

Parturition was not observed in ovariectomized mice if the silicone tube containing $E_{2}$ and MPA was left inside the mother. As the serum levels of both progesterone and $\mathrm{E}_{2}$ decline before parturition in normal pregnancy (Murr et al. 1974, Barkley et al. 1977), the decrease in progesterone appears to be essential in parturition. Mice deficient in the prostaglandin receptor that binds to prostaglandin F2 $\alpha$ cannot deliver their fetuses because the corpora lutea does not regress, and progesterone levels remain high (Sugimoto et al. 1997). In these mice, ovariectomy could induce parturition because of the decline in the sex steroids (Sugimoto et al. 1997). Ninety percent of ovariectomized mice underwent successful parturition by removal of the silicone tube containing $E_{2}$ and MPA (Table 1). The time-point of steroid removal was the start point of parturition in this study. This is a very useful model for analysis of the molecular mechanisms of parturition without functioning ovaries. The concentration of plasma $E_{2}$ was higher after parturition at ED24 $(n=2)$. $E_{2}$ derivative, $E_{2}$ benzoate used in this study, itself does not have high estrogenic activity as $E_{2}$ (Whitman et al. 1937). This derivative dissociates benzoate rapidly after administration into the body (Dunn et al. 1977). The antibody for $E_{2}$ inside the EIA system does not show any cross-reactivity with it. Therefore, the removal of MPA at ED23 might promote dissociation of benzoate very rapidly to produce $\mathrm{E}_{2}$.

The live pups were born alive, however, they all died within a day after parturition. It was because the mammary glands of the mothers did not grow well (Fig. 2). The pups from the normal mother were transferred to the ovariectomized mother. However, the pups could not live over $48 \mathrm{~h}$. Relaxin derived from the ovary is essential to develop the mammary gland (Zhao et al. 1999). The morphological structures of the mammary gland in ovariectomized mice were quite similar to those in the mice without a functional relaxin gene (Zhao et al. 1999). Previous study showed that the administration of relaxin extract from pregnant rabbit serum and/or pregnant sow ovaries improved the number of mice which reared their pups after ovariectomy at mid-pregnancy and subsequent maintenance by daily injection of progesterone and $E_{2}$ (Hall 1957).

Delivered pups from ovariectomized mother had been raised by the normal mother since immediately after parturition $(n=3)$. These pups did not grow under the foster mother (died in a day). The possible reasons why the pups from ovariectomized mice could not live long are as follows: 1 ) the levels of two steroids, MPA and $E_{2}$, are not high enough for the embryos to urge normal development (Murr et al. 1974, Barkley et al. 1977); and 2) the embryos require additional ovarian factors from the mother for normal development.

When we counted the number of pups in the morning after parturition, the number of delivered pups was 4.78 on an average, which was significantly less than the prospective number of implantation sites. It is possible that some pups were eaten by their mothers because their young died after birth accompanying maldevelopment of the mammary glands.

This is the first report on control of whole pregnancy in mice, from embryo implantation to parturition, by exogenous treatments without the ovaries. According to the protocol, almost all the mice could sustain pregnancy. Murine pregnancy is a very complicated process involving embryo implantation, placentation, and parturition and contains multiple cellular/tissue events. In addition to this, the timing of the initiation of each event depends on that of mating time (up to $12 \mathrm{~h}$ ). This model is quite helpful in the analysis of 
transcriptomes and proteomes in the uterus, because time-dependent events can be traced exactly at any time during pregnancy.

\section{Materials and Methods Animal}

All experimental procedures were performed under avertin anesthesia (Sigma-Aldrich) according to the guidelines established by the Committee for Animal Welfare at Nagoya University (approval number: 2010042803). ICR mice (Japan SLC, Shizuoka, Japan) of 8-12 weeks of age were used in the experiments. Mice were housed at $23 \pm 3{ }^{\circ} \mathrm{C}$ in controlled light-darkness cycles (1200 h light:1200 h darkness) and were fed ad libitum.

\section{Control of pregnancy}

The protocol of the experiment is described in Fig. 3A. Mice were ovariectomized between 1730 and $1900 \mathrm{~h}$ on D3 (D1 Evaginal plug), and MPA $(100 \mu \mathrm{l} / \mathrm{head}$; Pfizer Inc, New York, NY, USA) was injected s.c. at the dorsal limber region (Fig. 3B). I.p. injection with LIF (25 $\mu$ g/head), which can substitute estrogen (Chen et al. 2000), was given to induce embryo implantation at ED6. Because embryo implantation was occurred at D4 in normal pregnancy (McCormack \& Greenwald 1974), this experimental procedure was 2 days late compared to the normal pregnancy after embryo implantation. Recombinant LIF protein was prepared according to a previous report (Terakawa et al. 2011). A silicone tube containing $50 \mu \mathrm{l}$ of $25 \mu \mathrm{g} / \mathrm{ml} \mathrm{E}_{2}$ benzoate (Kyoritsu Seiyaku, Tokyo, Japan) was s.c. inserted at the dorsal region at ED11 (Fig. 3B), as a previous study reported that a silastic implant with $10-33 \mu \mathrm{g} / \mathrm{ml} \mathrm{E}_{2}$ was sufficient to maintain pregnancy during this period (Milligan \& Finn 1997, Okada et al. 2005). The silicone tube consists of inner silicone tube (i.d. $2 \mathrm{~mm}$, o.d. $3 \mathrm{~mm}$, and $20 \mathrm{~mm}$ in length; Kaneka Medix Corp, Osaka, Japan) and outer
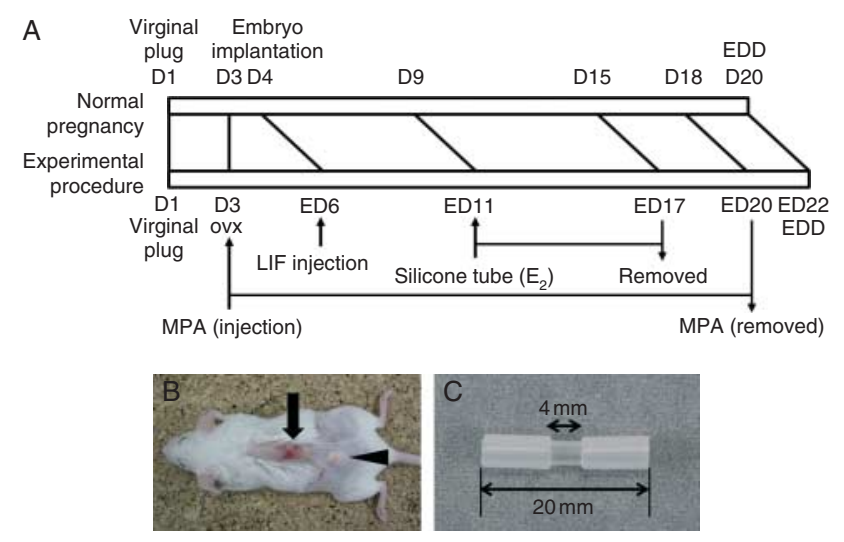

Figure 3 Experimental procedure to control pregnancy in mice (A). Medroxyprogesterone acetate (MPA) is injected (B, arrowhead) simultaneously with ovariectomy at D3. LIF administrated at ED6 induces embryo implantation. A silicone tube with $17 \beta$-estradiol $\left(E_{2}\right)$ is inserted at ED11 (B, arrow; and C). E2 and MPA are removed for parturition at ED17 and ED20 respectively. The EDD is ED22. polyethylene tube (i.d. $3 \mathrm{~mm}$, o.d. $4 \mathrm{~mm}$, and $8 \mathrm{~mm}$ in length; Imamura, Tokyo, Japan), and both sides of edge were covered by the silicone (Shin-Etsu Chemical Co Ltd, Tokyo, Japan) after $\mathrm{E}_{2}$ was infused (Fig. $3 \mathrm{C}$ ). The silicone tube was soaked in sterile saline before the day of transplantation. To deliver the fetuses, the silicone tube with $E_{2}$ was removed at ED17, and MPA was removed at ED20. The expected date of delivery (EDD) was ED22.

\section{Plasma levels of steroid hormones}

Blood samples $(n=3-5)$ from the mice of the experimental group were collected via the tail vein at ED5, 8, 11, 14, 17, 20, and 23 (or 24) respectively. Each plasma was isolated and stored at $-80{ }^{\circ} \mathrm{C}$ until the measurement. $E_{2}$ concentration was measured by the $E_{2}$ EIA kit (Cayman Chemical Company, Ann Arbor, MI, USA) according to the instruction manual. Detection limit of this assay system was $11.8 \mathrm{pg} / \mathrm{ml}$.

Plasma levels of MPA were determined by LC-MS/MS. Ten microliters of centrifuged supernatant from the mixture of $20 \mu \mathrm{l}$ of each plasma and $80 \mu \mathrm{l}$ of methanol (Wako, Osaka, Japan) were applied to ACQUITY Ultra Performance LC (UPLC; Waters, Milford, MA, USA) with ACQUITY UPLC HSS T3 column $(50 \times 2.1 \mathrm{~mm}$, i.d. $1.8 \mu \mathrm{m}$; Waters $)$ by the following conditions: flow rate, $0.4 \mathrm{ml} / \mathrm{min}$; column temperature, $40{ }^{\circ} \mathrm{C}$; and mobile phase, $0.1 \%$ formic acid (Wako)/methanol containing $0.1 \%$ formic acid. UPLC was connected with Micromass Quattro Premier XE Tandem Quadrupole Mass Spectrometer (Waters). The measurement condition was as follows: method: electrospray ionization, positive-mode; capillary voltage: $3.5 \mathrm{kV}$; cone voltage: $25 \mathrm{~V}$; collision energy: $15 \mathrm{eV}$; and precursor ion $\rightarrow$ product ion: $\mathrm{m} / \mathrm{z} 387.4 \rightarrow 327.1$. The concentrations of MPA in samples were calculated on the calibration curve, which was determined by the normal murine plasma containing known concentrations of MPA.

\section{Statistical analysis}

Statistical analysis was performed by one-way ANOVA. Values of $E_{2}$ at ED23 and ED24 were excluded from the statistical analysis because the number of samples was insufficient for one-way ANOVA.

\section{Evaluation of successful pregnancy}

The number of the placenta or living pups at term of pregnancy (ED22) was counted using mice, inside which the $E_{2}$ implant and MPA were left $(n=7)$. To confirm whether the fetuses were alive or not, their hind limbs were lightly pinched by the forceps immediately after the fetuses were picked out from the uterus. Delivered pups were counted on the peri-EDD $(n=10)$. Mothers were sacrificed after parturition, and the number of the metrial glands, which is the number of predicted implantation sites, was counted. The mammary gland was collected at ED23 in ovariectomized mice and at D21 in normal pregnant mice respectively. Samples were fixed in Bouin's solution and paraffinized by the conventional procedure. Four micrometer section was prepared and stained with hematoxylin and eosin. 


\section{Declaration of interest}

The authors declare that there is no conflict of interest that could be perceived as prejudicing the impartiality of the research reported.

\section{Funding}

This study was partly supported by grants-in-aid for Scientific Research (grant number 20380161) and a grant-in-aid for JSPS Fellows (grant number 229587) from the Japan Society for the Promotion of Science.

\section{References}

Albrecht ED, Aberdeen GW \& Pepe GJ 2000 The role of estrogen in the maintenance of primate pregnancy. American Journal of Obstetrics and Gynecology 182 432-438. (doi:10.1016/S0002-9378(00)70235-3)

Barkley MS, Michael SD, Geschwind Br II \& adford GE 1977 Plasma testosterone during pregnancy in the mouse. Endocrinology $\mathbf{1 0 0}$ 1472-1475. (doi:10.1210/endo-100-5-1472)

Bland KP \& Donovan BT 1969 Control of luteal function during early pregnancy in the guinea-pig. Journal of Reproduction and Fertility $\mathbf{2 0}$ 491-501. (doi:10.1530/jrf.0.0200491)

Chen JR, Cheng JG, Shatzer T, Sewell L, Hernandez L \& Stewart CL 2000 Leukemia inhibitory factor can substitute for nidatory estrogen and is essential to inducing a receptive uterus for implantation but is not essential for subsequent embryogenesis. Endocrinology 141 4365-4372. (doi:10.1210/en.141.12.4365)

Csapo Al, Pulkkinen MO, Ruttner B, Sauvage JP \& Wiest WG 1972 The significance of the human corpus luteum in pregnancy maintenance. I. Preliminary studies. American Journal of Obstetrics and Gynecology $\mathbf{1 1 2}$ 1061-1067.

Dunn TG, Kaltenbach CC, Koritnik DR, Turner DL \& Niswender GD 1977 Metabolites of estradiol-17 $\beta$ and estradiol-17 $\beta$-3-benzoate in bovine tissues. Journal of Animal Science $\mathbf{4 6}$ 659-673.

Estergreen VL, Frost OL, Gomes WR, Erb RE \& Bullard JF 1967 Effect of ovariectomy on pregnancy maintenance and parturition in dairy cows. Journal of Dairy Science 50 1293-1295. (doi:10.3168/jds.S00220302(67)87615-X)

Hall K 1957 The effect of relaxin extracts, progesterone and oestradiol on maintenance of pregnancy, parturition and rearing of young after ovariectomy in mice. Journal of Endocrinology 15 108-117. (doi:10. 1677/joe.0.0150108)

Hinrichs K, Sertich PL, Palmer E \& Kenney RM 1987 Establishment and maintenance of pregnancy after embryo transfer in ovariectomized mares treated with progesterone. Journal of Reproduction and Fertility $\mathbf{8 0}$ 395-401. (doi:10.1530/jrf.0.0800395)

Holmes PV \& Bergström S 1975 Induction of blastocyst implantation in mice by cyclic AMP. Journal of Reproduction and Fertility 43 329-332. (doi:10.1530/jrf.0.0430329)
Kusakabe K, Naka M, Ito Y, Eid N \& Otsuki Y 2008 Regulation of naturalkiller cell cytotoxicity and enhancement of complement factors in the spontaneously aborted mouse placenta. Fertility and Sterility 90 1451-1459. (doi:10.1016/j.fertnstert.2007.07.1331)

McCormack JT \& Greenwald GS 1974 Evidence for a preimplantation rise in oestradiol-17 $\beta$ levels on day 4 of pregnancy in the mouse. Journal of Reproduction and Fertility 41 297-301. (doi:10.1530/jrf.0.0410297)

Meites J, Webster HD, Young FW, Thorp F \& Hatch RN 1951 Effects of corpora lutea removal and replacement with progesterone on pregnancy in goats. Journal of Animal Science 10 411-416.

Milligan SR \& Finn CA 1997 Minimal progesterone support required for the maintenance of pregnancy in mice. Human Reproduction 12 602-607. (doi:10.1093/humrep/12.3.602)

Murr SM, Stabenfeldt GH, Bradford GE \& Geschwind II 1974 Plasma progesterone during pregnancy in the mouse. Endocrinology $\mathbf{9 4}$ 1209-1211. (doi:10.1210/endo-94-4-1209)

Okada A, Niwa Y, Katase T \& Kai O 2005 Controlled release of estradiol17 ? $\beta$ and bisphenol $A$ from a siliconee tube for long-term administration in mice. Animal Science Journal 76 535-539. (doi:10.1111/j.1740-0929. 2005.00301.x)

Pickworth S \& Lamming GE 1967 Observations on pregnancy in intact rabbits and in ovariectomized rabbits treated with 17 $\alpha$-hydroxyprogesterone caproate. Journal of Reproduction and Fertility 13 457-468. (doi:10.1530/jrf.0.0130457)

Rubinstein L \& Forbes TR 1963 Maintenance of pregnancy with subcutaneous pellets of progesterone in ovariectomized mice. Proceedings of the Society for Experimental Biology and Medicine 113 1043-1046. (doi:10.3181/00379727-113-28567)

Sugimoto Y, Yamasaki A, Segi E, Tsuboi K, Aze Y, Nishimura T, Oida H, Yoshida N, Tanaka T, Katsuyama M et al. 1997 Failure of parturition in mice lacking the prostaglandin F receptor. Science 277 681-683. (doi:10.1126/science.277.5326.681)

Terakawa J, Wakitani S, Sugiyama M, Inoue N, Ohmori Y, Kiso Y, Hosaka YZ \& Hondo E 2011 Embryo implantation is blocked by intraperitoneal injection with anti-LIF antibody in mice. Journal of Reproduction and Development $\mathbf{5 7} 700-707$.

Verstegen-Onclin K \& Verstegen J 2008 Endocrinology of pregnancy in the dog: a review. Theriogenology 70 291-299. (doi:10.1016/j.theriogenology.2008.04.038)

Whitman B, Wintersteiner O \& Schwenk E 1937 ß-Estradiol. Journal of Biological Chemistry 118 789-795.

Wu JT \& Chang MC 1972 Effects of progesterone and estrogen on the fate of blastocysts in ovariectomized pregnant ferrets: a preliminary study. Biology of Reproduction 7 231-237.

Zhao L, Roche PJ, Gunnersen JM, Hammond VE, Tregear GW, Wintour EM \& Beck F 1999 Mice without a functional relaxin gene are unable to deliver milk to their pups. Endocrinology 140 445-453. (doi:10.1210/en. 140.1.445)

Received 9 August 2011

First decision 16 September 2011

Revised manuscript received 2 December 2011

Accepted 22 December 2011 